\title{
Laboratory simulation of carbon dioxide corrosion, influence of alloying elements and hydrochloric acid on the structure and protective properties of corrosion products
}

\author{
Dmitry Kazadaev ${ }^{1 *}$ \\ ${ }^{1}$ IT Service, Samara, Russian Federation
}

\begin{abstract}
The paper considers the modeling of $\mathrm{CO}_{2}$-corrosion on chromium-containing steels $1-5 \%$. Study of the protective properties of a layer of corrosion products on steels with a chromium content of $1-5 \%$ and the effect of periodic hydrochloric acid treatments.
\end{abstract}

\section{Introduction}

Transportable environments of oil and gas deposits (Eastern and Western Siberia, the Volga region, the Orenburg region, the Komi Republic, etc.) contain an excessive concentration of carbon dioxide, which leads to premature pit corrosion of oil and gas pipes.

Currently, there is no model and methodology for assessing the mechanism and rate of carbon dioxide corrosion.

This paper is devoted to the problem of modeling and studying the regularities of the flow of $\mathrm{CO}_{2}$-corrosion depending on the chemical composition of steels.

The author [1] presents the results of a study of the effect of chemical elements with amphoteric properties in compounds of $\mathrm{Cr}, \mathrm{V}, \mathrm{Mo}, \mathrm{Si}$, etc., which affect the increase in the resistance of steels to pit carbonic acid corrosion.

Steels with a chromium content of 0.7 to $5 \mathrm{wt} . \%$ are the objects of the re-search. They are presented in Table 1.

Table 1. Chemical composition of the samples under study.

\begin{tabular}{|c|c|c|c|c|c|c|}
\hline № & Steel grade & C & $\mathrm{Cr}$ & Mo & $\mathbf{V}$ & \multirow{4}{*}{$\begin{array}{c}\mathrm{Fe} \\
\text { and } \\
\text { inevitable } \\
\text { impurities }\end{array}$} \\
\hline 1 & $\begin{array}{c}\text { Low alloyed } \\
\text { steel } \\
(0.13 \mathrm{Cr} 1 \mathrm{~V})\end{array}$ & 0.14 & 0.61 & - & 0.04 & \\
\hline 2 & $\begin{array}{c}\text { Low alloyed } \\
\text { steel } \\
(0,15 \mathrm{Cr} 2 \mathrm{MoV})\end{array}$ & 0.15 & 2.13 & 0.22 & 0.09 & \\
\hline 3 & $\begin{array}{c}\text { Low alloyed } \\
\text { steel } \\
(0.15 \mathrm{Cr} 5 \mathrm{MoV})\end{array}$ & 0.15 & 5.10 & 0.53 & 0.11 & \\
\hline
\end{tabular}

\section{Experimenting}

$\mathrm{CO}_{2}$ corrosion was simulated in a thermostat at $\mathrm{T}=65^{\circ} \mathrm{C}$. The model solution was purged with nitrogen to remove dissolved oxygen. Then it was saturated with ultrapure carbon dioxide. The acidity of the resulting solution was $\mathrm{pH}=3.5$. Then the solution was pumped under pressure into a container with samples. The test lasted 400 hours. Figure 1 shows the installation diagram.

The polished metal plates $4 \times 10 \times 25 \mathrm{~mm}$ made from oil-field pipes were selected as samples for the study.

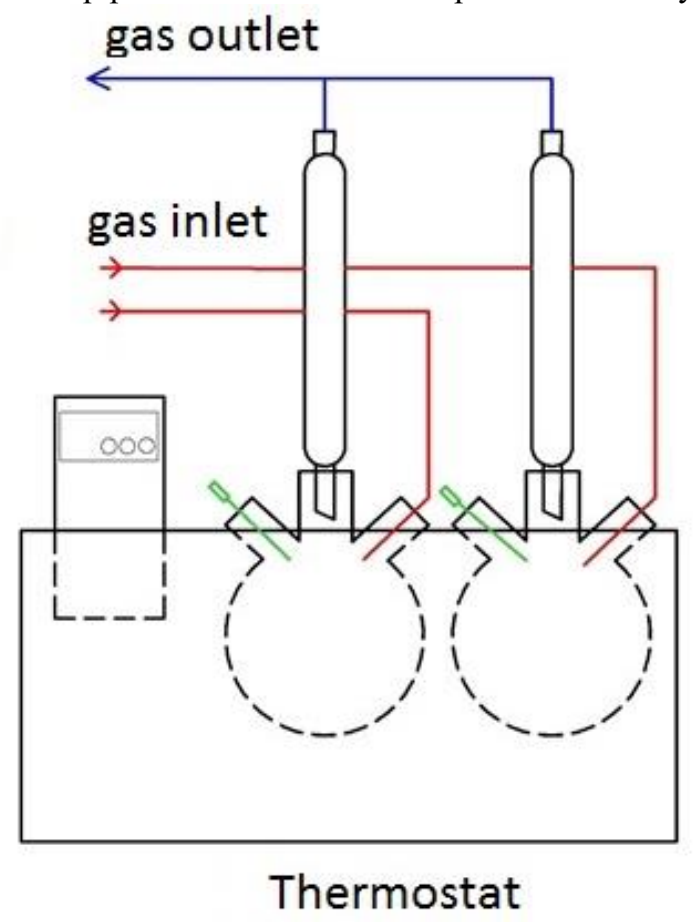

Fig. 1. Scheme of a laboratory setup for research of $\mathrm{CO}_{2}$ corrosion.

Reliability of the results obtained in laboratory simulation was confirmed by a comparative analysis of the corrosion products formed on the inner surface of pipes after long-term operation in environments with a concentration of $\mathrm{CO}_{2}$ close to the model one.

\footnotetext{
* Corresponding author: kazadaev@its-samara.com
} 
According to the technological regulations, hydrochloric acid can be used in the oil production process to increase the productivity of the deposits [2]. Due to this fact, we carried out an additional study of the effect of repetitive additives of hydrochloric acid (with its concentration as close as possible to real conditions) on damageability of $\mathrm{CO}_{2}$-corrosion products.

\section{Analysis of the obtained results}

Figure 2 shows the products of corrosion formed on the surface of the samples in laboratory conditions. The process took 400 hours.

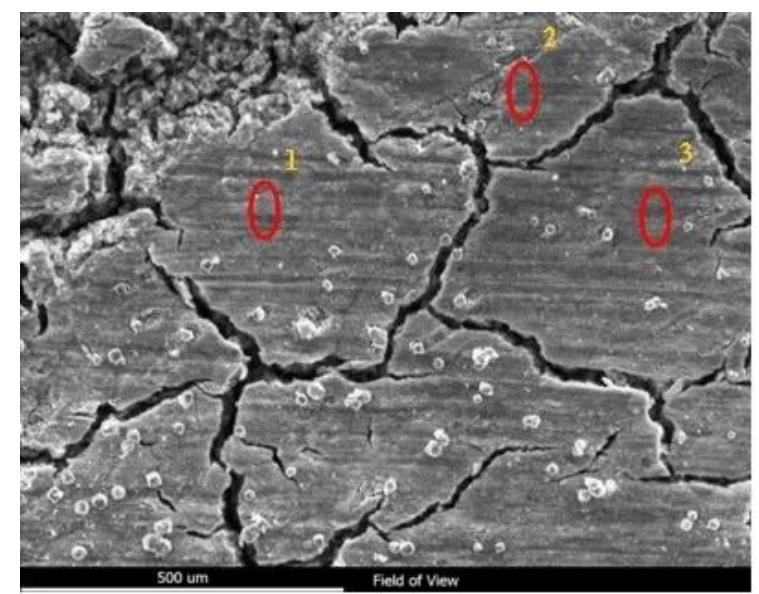

A

\begin{tabular}{|c|c|c|c|c|}
\hline Element & O & Cr & V & Fe \\
\hline Area 1 & 21.02 & 6.59 & 0.45 & \\
\cline { 1 - 4 } Area 2 & 22.83 & 5.73 & 0.43 & \multirow{2}{*}{ Rest } \\
\cline { 1 - 3 } Area 3 & 19.96 & 14.18 & 1.15 & \\
\hline
\end{tabular}

Fig. 2. Type of corrosion products (A) and their chemical composition (B) on the surface of the sample under laboratory conditions for 400 hours.

An XL30 scanning electron microscope (Philips) was used to investigate the corrosion products. Local chemical analysis of the surface was carried out on an energy dispersive detector (EDAX). A significant increase in the concentration of $\mathrm{Cr}, \mathrm{V}$ in the corrosion products relative to the metal composition was detected.

Figure 3 presents a sectional view of corrosion products. Corrosion products are dense; their thickness is $\sim 110$ microns. An increased content of $\mathrm{O}, \mathrm{V}$, and $\mathrm{Cr}$ is observed in the corrosion products.

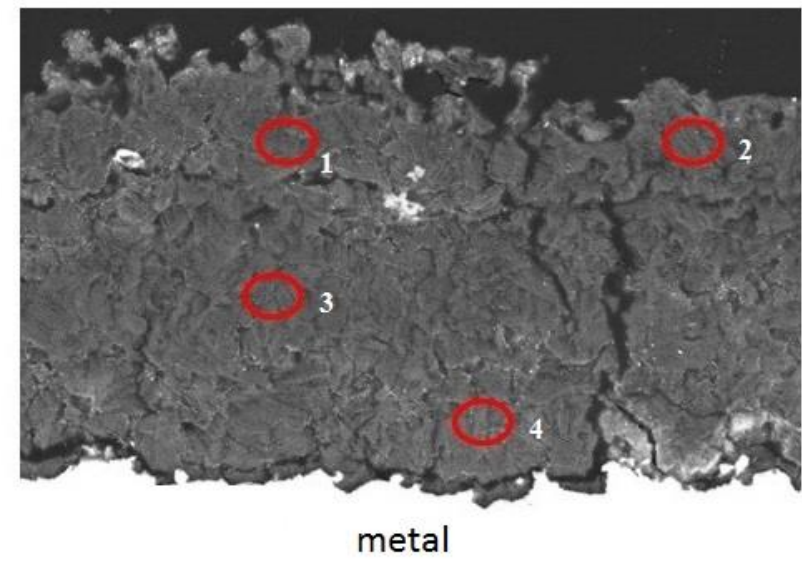

A

\begin{tabular}{|c|c|c|c|c|}
\hline Element & $\mathbf{O}$ & $\mathbf{C r}$ & $\mathbf{V}$ & Fe \\
\cline { 1 - 4 } Area 1 & 28.30 & 5.97 & 0.45 & \\
\cline { 1 - 4 } Area 2 & 20.31 & 5.90 & 0.44 & \multirow{2}{*}{ Rest } \\
\cline { 1 - 3 } Area 3 & 22.39 & 2.4 & 0.40 & \\
\cline { 1 - 3 } Area 4 & 22.70 & 2.01 & 0.38 & \\
\hline
\end{tabular}

Fig. 3. The structure of corrosion products (A) and their chemical composition (B) in the sample section.

X-ray diffraction analysis did not reveal reflexive actions specific to crystalline iron carbonate.

According to the previous studies $[3,4]$, if chromium interacts with a $\mathrm{CO}_{2}$-containing medium, it leads to the formation of complex polyhydroxides, which are capable of exhibiting amphoteric properties. Such products of corrosion have an amorphous structure [5].

To prove the structure of the formed corrosion products, we carried out a thermal analysis.

The results of the TG-DSC-MS analysis are shown in Figure 4.

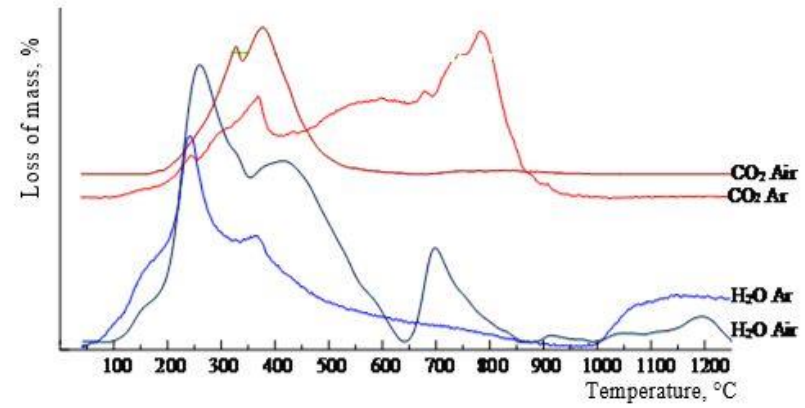

Fig. 4. Thermogram of synchronous thermal analysis.

As it can be seen from the thermoanalytical and mass spectrometric curves, the thermolysis of the sample includes many stages corresponding to a large number of chemical transformations that flow differently in the argon atmosphere. 
The emission of gases in argon occurs in two stages. The first stage (with maxima of about 200 and $420^{\circ} \mathrm{C}$ ) corresponds to the removal of chemically bound water (elimination of water from the terminal and bridging $\mathrm{OH}$ groups, respectively). The second stage of the release of carbon dioxide is most likely linked with the thermal destruction of iron hydroxycarbonate.

Thus, it was possible to identify hydroxide and carbonate ions that have a non-crystalline structure in the composition of corrosion products.

The graph (Fig. 5) shows the dependence of the concentration of iron (II) in the model solution for steel grades that differ in the concentration of chromium.

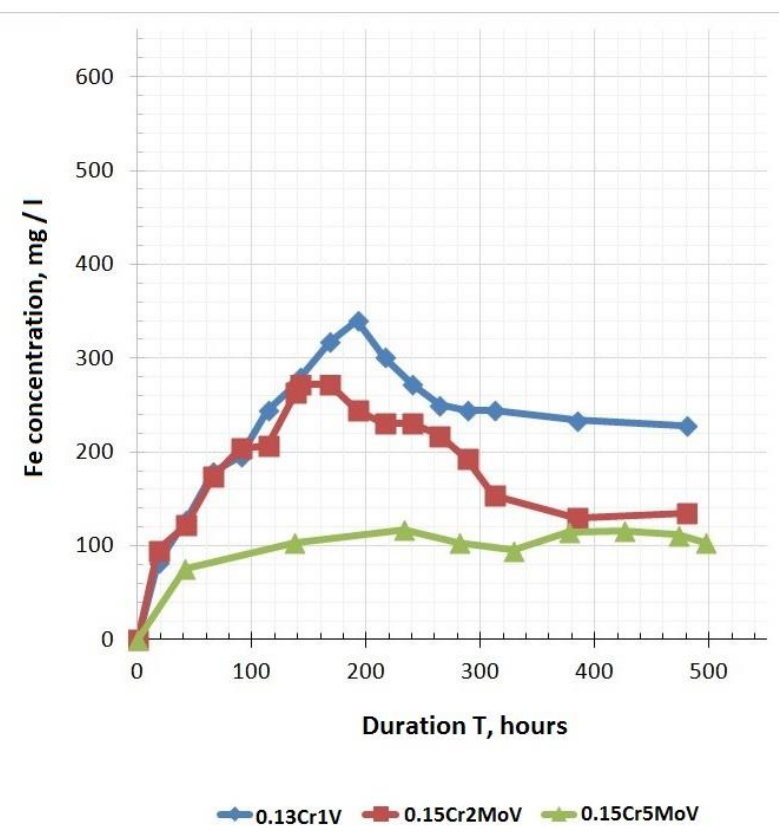

Fig. 5. Dependence of the concentration of iron (II) on the duration of the test.

The analyzed curves can be divided into 2 stages:

1) Formation of a layer of carbon dioxide corrosion products;

2) The stage of stabilization, at which the concentration of Fe (II) in the solution practically does not change. This means that the process of the formation of $\mathrm{CO}_{2}$-corrosion products has ended. A protective layer has been formed on the surface of the samples, which prevents interaction of the environment with the metal surface.

For steels containing $0.61 \%$ and $2.10 \mathrm{wt} \% \mathrm{Cr}$., the first stage ends after 300 hours of exposure. At the same time, the $\mathrm{Fe}$ (II) concentration for steel with chromium content of $2.10 \mathrm{wt} \%$ is lower by $\sim 100 \mathrm{mg} /$ $\mathrm{dm} 3$ than for steel with a chromium content of $0.61 \mathrm{wt} \%$.

For low alloyed steel $(0.15 \mathrm{Cr} 5 \mathrm{MoV})$, changes in the $\mathrm{Fe}$ (II) con-centration in a model environment differ significantly from steels of grades $0.13 \mathrm{Cr} 1 \mathrm{~V}$ and $0.15 \mathrm{Cr} 2 \mathrm{MoV}$ : hours;

- the first stage is completed after holding for $\sim 50$

- the corrosive layer formed during exposure in a model $\mathrm{CO}_{2}$-containing environment has high protective properties: concentration of $\mathrm{Fe}$ (II) is stable and is at the level of $\sim 100 \mathrm{mg} / \mathrm{dm} 3$.

Thus, the corrosion rate in a $\mathrm{CO}_{2}$-containing environment for samples made of low alloyed steel $(0.15 \mathrm{Cr} 5 \mathrm{MoV})$ is lower than for $0.13 \mathrm{Cr} 1 \mathrm{~V}$ and $0.15 \mathrm{Cr} 2 \mathrm{MoV}$ low alloyed steels.

\section{Analysis of the influence of hydrochloric acid treatments on the formed layer of corrosion products on the alloy}

The following are the results of the influence of periodic hydro-chloric acid treatments on the structure and phase composition of $\mathrm{CO}_{2}$-corrosion products.

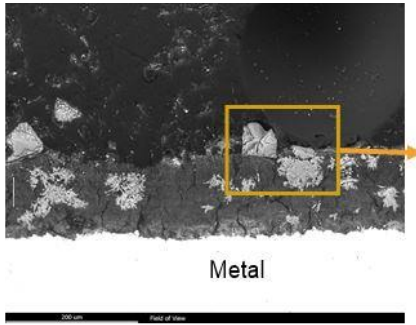

Crystalline carbonate

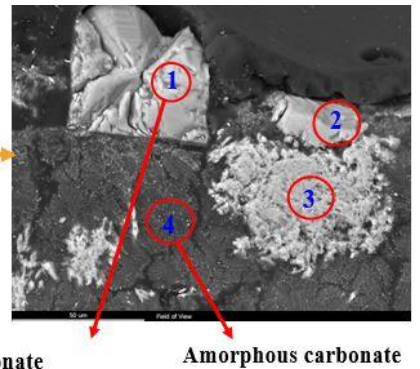

A

\begin{tabular}{|c|c|c|c|c|c|}
\hline Element & $\mathbf{O}$ & $\mathrm{Cr}$ & $\mathbf{V}$ & Cl & Fe \\
\hline \multicolumn{6}{|c|}{ After testing for resistance to $\mathrm{CO}_{2}$ corrosion } \\
\hline Area 1 & 36.1 & - & - & - & \multirow{4}{*}{ Rest } \\
\hline Area 2 & 27.3 & 1.2 & - & - & \\
\hline Area 3 & 26.3 & 2.0 & - & 0.3 & \\
\hline Area 4 & 33.7 & 5.3 & 0.45 & 7.2 & \\
\hline \multicolumn{6}{|c|}{ Metal composition as delivered } \\
\hline Metal & - & 0.61 & 0.04 & - & Rest \\
\hline
\end{tabular}

Fig. 6. The structure of the corrosion products $(\mathrm{A})$ and their chemical composition (B) on the surface of $0.13 \mathrm{Cr} 1 \mathrm{~V}$ low alloyed steel samples in the cross-section formed in the $\mathrm{CO}_{2}-$ containing environment (hydrochloric acid is added).

The micrographs show (Fig. 6) that amorphous corrosion products are de-stroyed and crystalline iron carbonates $\mathrm{FeCO}_{3}$ are formed, which is proved by the results of epy X-ray structural analysis phase.

Similar processes of destruction of amorphous corrosion products and the formation of crystalline carbonates on the surface are observed for low alloyed steel (0.15Cr2MoV) (Fig. 7). 


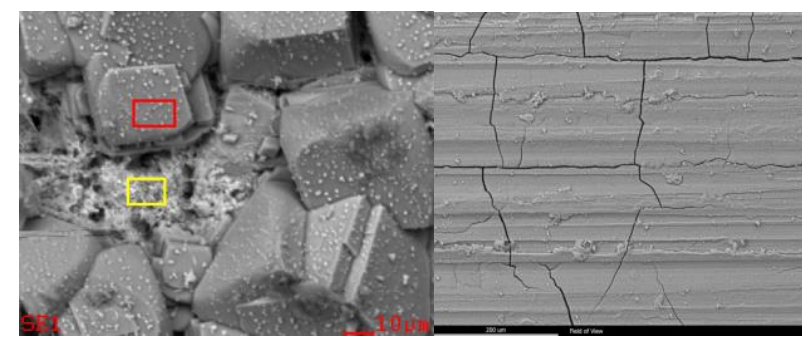

A

B

A) low alloyed steel $0.15 \mathrm{Cr} 2 \mathrm{MoV}$; B) low alloyed steel $0.15 \mathrm{Cr} 5 \mathrm{MoV}$

Fig. 7. Corrosion products on the surface of the samples formed in a model $\mathrm{CO}_{2}$-containing environment with the addition of hydrochloric acid.

Steel $0.15 \mathrm{Cr} 5 \mathrm{MoV}$ is practically unaffected by hydrochloric acid, there are no crystalline carbonates. The layer is homogeneous.

The nature of the change in the concentration of $\mathrm{Fe}$ (II) for $0.13 \mathrm{Cr} 1 \mathrm{~V}, 0.15 \mathrm{Cr} 2 \mathrm{MoV}$ and $0.15 \mathrm{Cr} 5 \mathrm{MoV}$ low alloyed steels with repetitive hydrochloric acid treatments (every 48 hours) are shown in Figure 8 (arrows indicate the addition of 5\% hydrochloric acid solution).

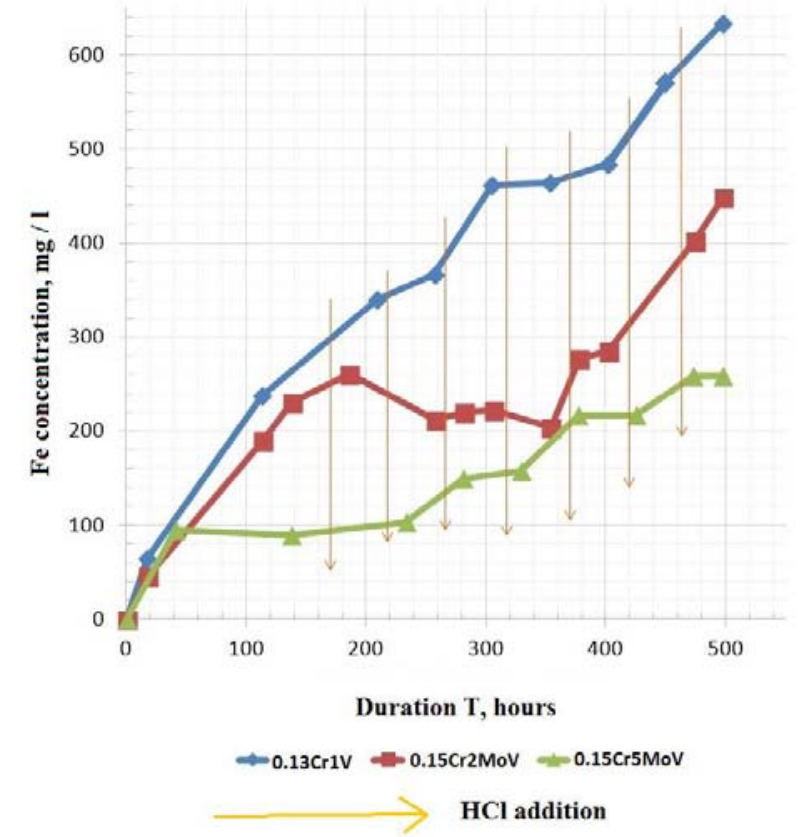

Fig. 8. Corrosion products on the surface of the samples formed in a model $\mathrm{CO}_{2}$-containing environment with the addition of hydrochloric acid - A) low alloyed steel $0.15 \mathrm{Cr} 2 \mathrm{MoV}$; B) low alloyed steel $0.15 \mathrm{Cr} 5 \mathrm{MoV}$.

The presented results correlate with the results of the assessment of the corrosion rate of the samples ( $\mathrm{mm}$ per year) in the model $\mathrm{CO}_{2}$-containing environment. The addition of $10 \%$ hydrochloric acid was taken into account. (Fig. 9).

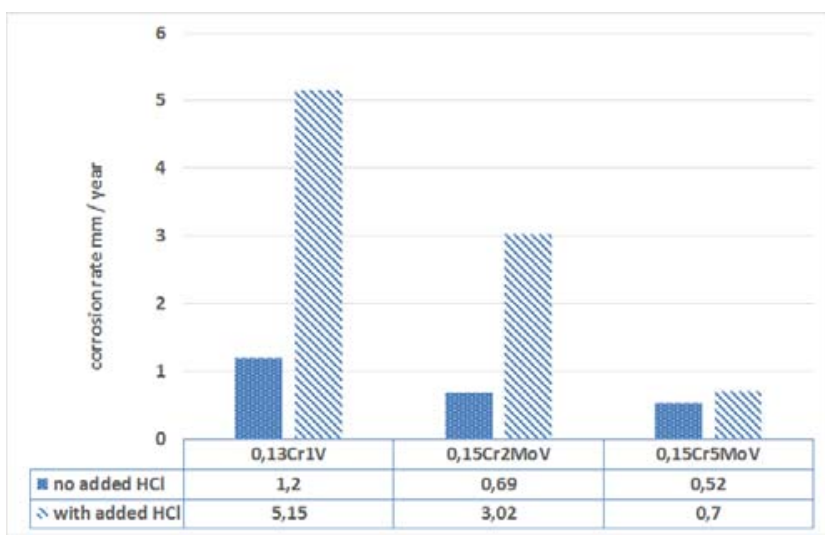

Fig. 9. Corrosion rate of samples in a model $\mathrm{CO}_{2}$-containing environment (addition of $10 \%$ hydrochloric acid is taken into account).

\section{Conclusion}

1. In the process of $\mathrm{CO}_{2}$-corrosion, corrosion products (both under laboratory and field conditions) are formed with an amorphous structure with a high content of $\mathrm{V}$, $\mathrm{Cr}, \mathrm{Si}$.

2. Hydrochloric acid treatments can affect corrosion products, which leads to the formation of crystalline carbonates and destruction of the metal.

\section{References}

1. Pessu F., Barker R., Neville A., Understanding pitting corrosion behavior of X65 carbon steel in $\mathrm{CO}_{2}$ - saturated environments: the temperature effect (Corrosion, Vol. 72, No. 1, 2016)

2. Kashchavtsev V.E., Study of conditions of gypsum deposition and methods of dealing with its deposits in the process of oil field development, (1974)

3. Chen C., Lu M., Sun D., Zhang Z., Chang W.., Effect of Chromium on the Pitting Resistance of Oil Tube Steel in a Carbon Dioxide (Corrosion, 61, 2005)

4. R. Ripan, I. Chityanu. Inorganic chemistry. Volume 2, Chemistry of metals (1972)

5. Chena T., Xua L., Lua M., Changb W., Zhanga L., Study on factors affecting low Cr alloy steels in a $\mathrm{CO}_{2}$ (Corrosion, Paper No. 74, 2011) 